\title{
A Comparative Study of Motor Stator Current Analysis and Instantaneous Power Analysis Techniques for the Diagnosis of Gear Faults under Medium Load Conditions
}

\author{
Alwadie. A \\ Faculty of Engineering, Electrical Engineering Department, Najran University \\ King Abdulaziz Road, Najran, Saudi Arabia \\ alwadie@hotmail.com
}

\begin{abstract}
Gears are used in the machines to transfer rotational mechanical power. The excessive vibration is produced due to malfunction of the gear which eventually causes machine breakdowns. Conventional vibration analysis method could reliably diagnose the gear faults but high cost of the vibration transducers is the main limitation of this technique. The non-intrusive stator current analysis has been the best alternative to vibration analysis technique. But the capability of the stator current analysis has been reported only on the full load conditions of the motor. This paper presents an alternative nonintrusive condition monitoring technique which utilize the both stator current and voltage to analyze the gear faults in instantaneous power spectra. The experimental test rig has been designed to compare the amplitude sensitivity of the stator current spectra and instantaneous power spectra for gear operating under medium load condition.
\end{abstract}

Keywords: Gear Fault Diagnosis, Condition Monitoring, Reliable Fault Identification System.

\section{Introduction}

Gears are used in mechanical power transformation from one shaft to other shaft. As the various elements of the machine are interconnected through gears thus, the healthy and smooth operation of gears is important for reliable and cost effective operation of the machine [1]. The unplanned shutdowns and catastrophic failures of the machine cause huge production loss and could be avoided through continuous condition monitoring technique. Various researchers have reported vibration analysis, temperature analysis, sound analysis, acoustic emission, noninvasive motor stator current analysis techniques to estimate the health of the gears [2-4]. The selection of the proper condition monitoring technique depends on the various factors such as: data measurement technique, transducers cost, installation of the transducers and reliability of the measured data.

The use of vibration analysis technique for the gear condition monitoring has been reported in several studies [5]. Although vibration analysis has been shown to be reliable and basic method for diagnosis of gear faults but high cost of the vibration transducers is the main limitation of this method. The nonintrusive motor stator current analysis has been used by few researchers to overcome the shortcomings of the vibration analysis method [6,7]. Although, stator current analysis is best alternative to vibration analysis technique for the development of an economical and versatile condition monitoring system, however, most of the researchers have used this method only on full load condition. As the majority of the machines are operated at medium load conditions, thus, the effectiveness and reliability of the stator current analysis should be tested for medium load conditions.

Recently, another non-intrusive condition monitoring technique based on the analysis of instantaneous power spectrum for bearing fault diagnosis has been reported by the researchers. It was shown that instantaneous power analysis technique possess a much better capability for detecting bearing defects. However, the detail comparison of the stator current analysis and instantaneous power analysis techniques for gear fault diagnosis under medium load conditions has not been performed in previous studies $[8,9,10]$.

The main contributions of this paper are 1) The design of the unique experiment set-up using cost effective transducers and integration of the transducers with LabVIEW to analyze amplitude sensitivity of gear fault harmonics. 2) Comparative study of the instantaneous power spectra and stator current spectra for motor-coupled gear operating under medium load condition.

\section{Design of Test Set-Up}

The experiments were conducted on the custom designed test set-up which consist of a motor, a gear box and a variable frequency drive (VFD). The designed set-up has been shown in Figure 1. The data was acquired from the current transducer and 
voltage transducer using National Instruments data acquisition system and then analyzed in the LabVIEW. The LabVIEW program routines developed for the motor current signature analysis and instantaneous power analysis are shown in Figure 2. The characteristic defect frequencies for the motor stator current spectrum and instantaneous power spectrum were calculated using the mathematical model as described in $[8,9$, 10] and are shown in the Table I.

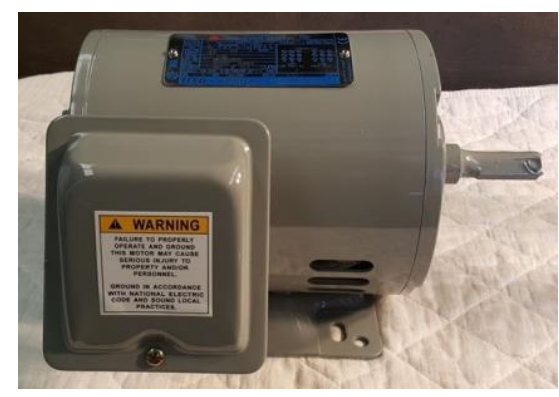

(a)

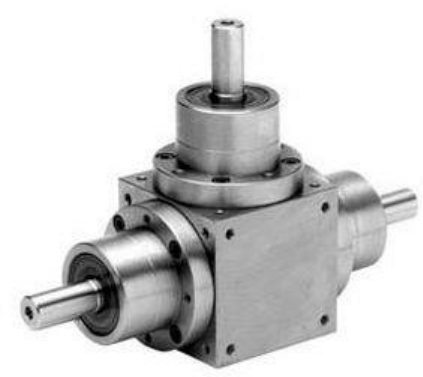

(b)

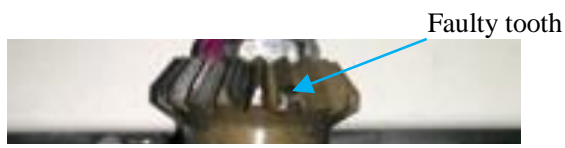

(c)

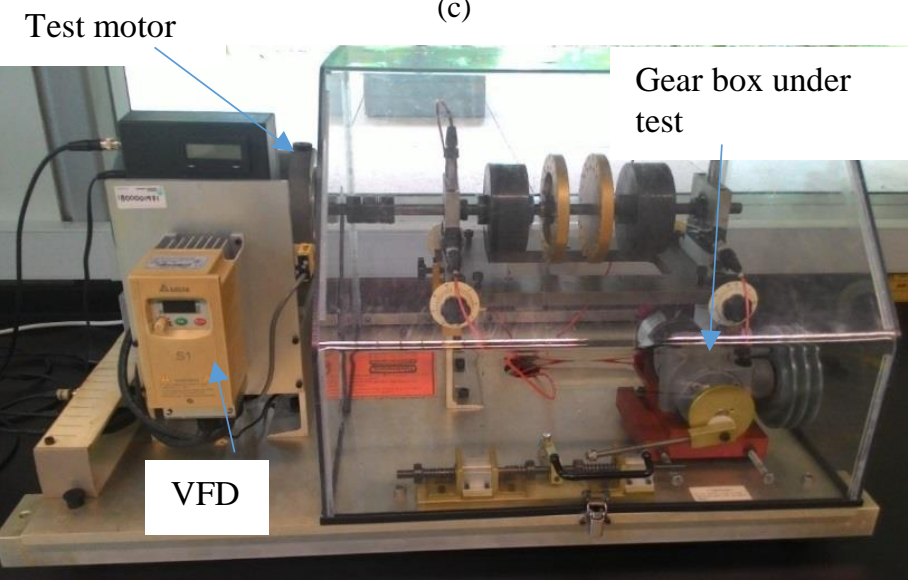

(d)

Fig. 1. The hardware used in the experiments (a) induction motor (b) gear box (c) faulty gear tooth (d) complete hardware integration 


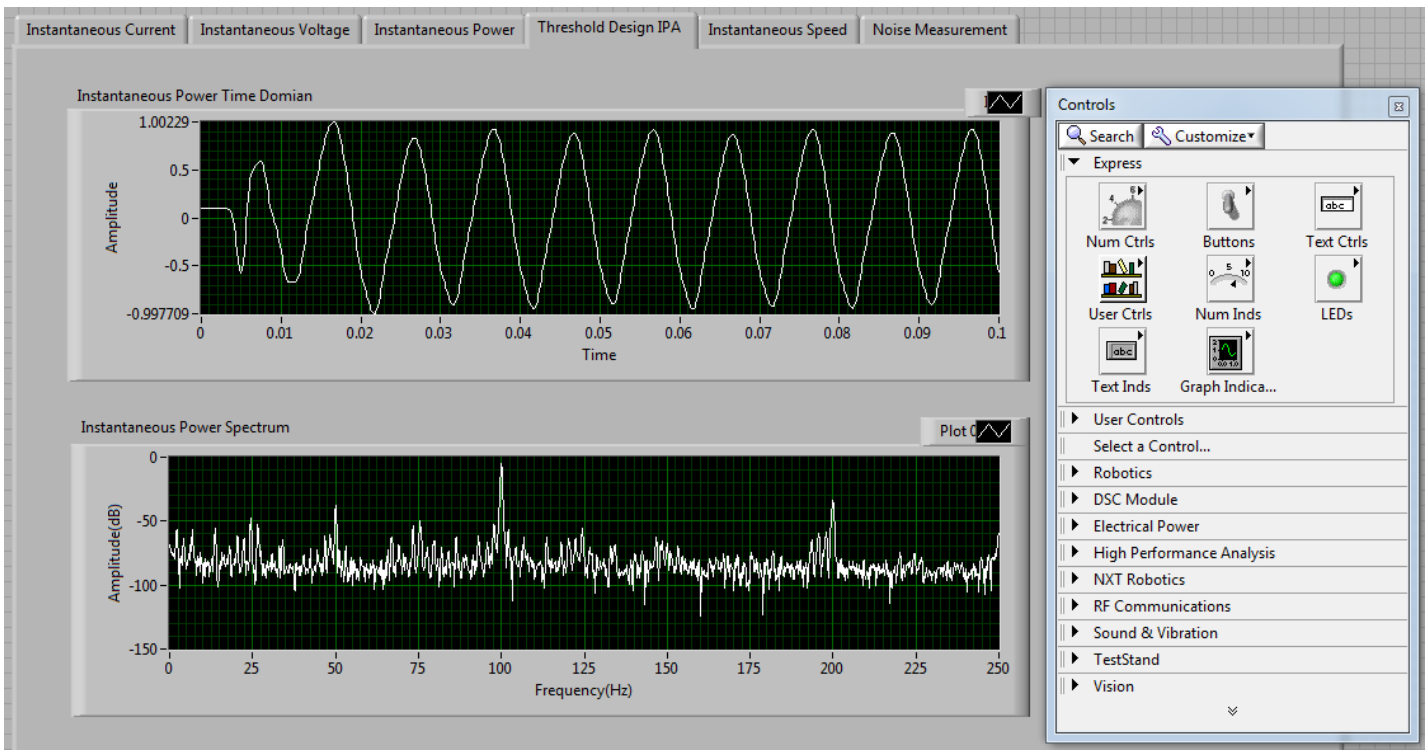

(a)

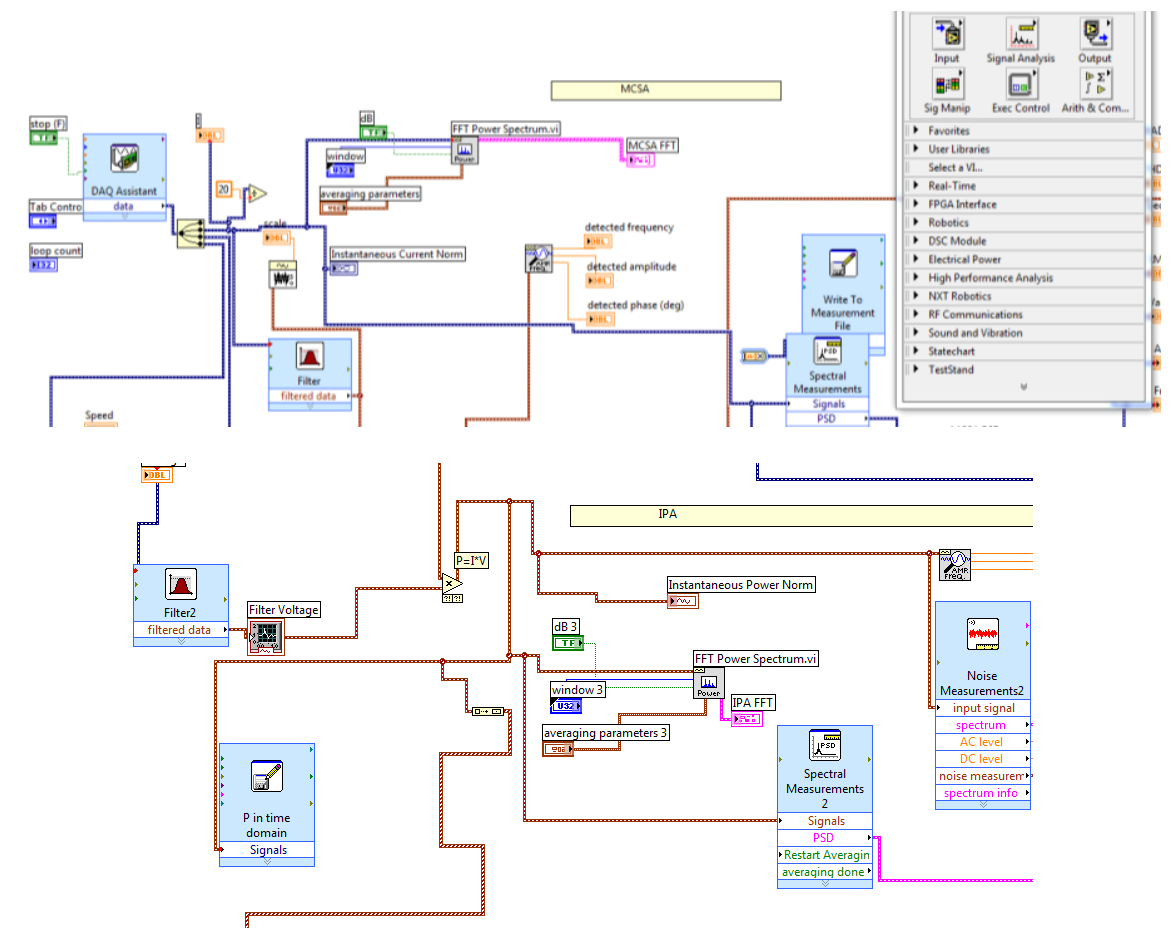

(b)

Fig. 2. The LabVIEW program routines (a) front panel diagram (b) block diagram

Table I. Gear Fault Harmonics for Stator Current and Instantaneous Power Spectra

\begin{tabular}{|c|c|c|c|c|c|}
\hline \multirow{2}{*}{$\begin{array}{c}\text { Motor Speed } \\
(\mathrm{rpm})\end{array}$} & \multicolumn{2}{|c|}{ Harmonics for stator current spectra } & \multicolumn{2}{|c|}{ Harmonics for instantaneous power spectra } \\
\cline { 2 - 6 } & $\begin{array}{c}\text { Lower Side Band } \\
(\mathrm{Hz})\end{array}$ & $\begin{array}{c}\text { Upper Side } \\
\text { Band }(\mathrm{Hz})\end{array}$ & $f_{g}(\mathrm{~Hz})$ & $\begin{array}{c}\text { Lower Side } \\
\text { Band }(\mathrm{Hz})\end{array}$ & $\begin{array}{c}\text { Upper Side } \\
\text { Band (Hz) }\end{array}$ \\
\hline 1415 & 26.4 & 73.6 & 23.6 & 76.4 & 123.6 \\
\hline
\end{tabular}




\section{Results and Discussions}

A. Case Study 1: Gear fault analysis using instantaneous power spectra

The instantaneous power analysis of the motor-coupled gear are shown in Figure 3. The amplitude values at harmonic frequencies $(23.6 \mathrm{~Hz}, 76.4 \mathrm{~Hz}$ and $123.6 \mathrm{~Hz})$ for the healthy gear are observed to be $-86.44 \mathrm{~dB},-67.43 \mathrm{~dB}$ and $-60.68 \mathrm{~dB}$. While the amplitude values for the faulty gear are shown to be -79.34 $\mathrm{dB},-60.19 \mathrm{~dB}$ and $-53.18 \mathrm{~dB}$. Thus, a total of $7 \mathrm{~dB}$ change in the amplitude has been observed as we replace the healthy gear with the faulty gear.

The summary of the amplitude variations at gear defect frequencies has been given in Table II.

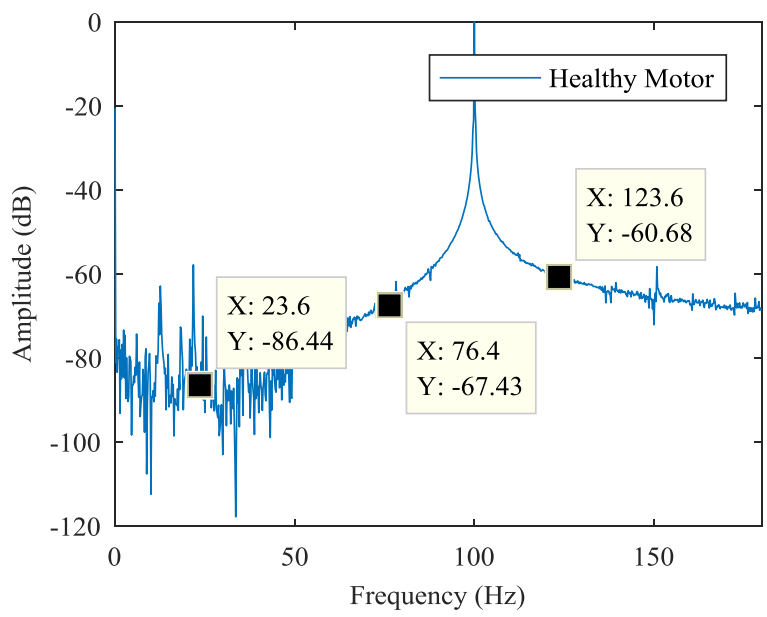

(a)

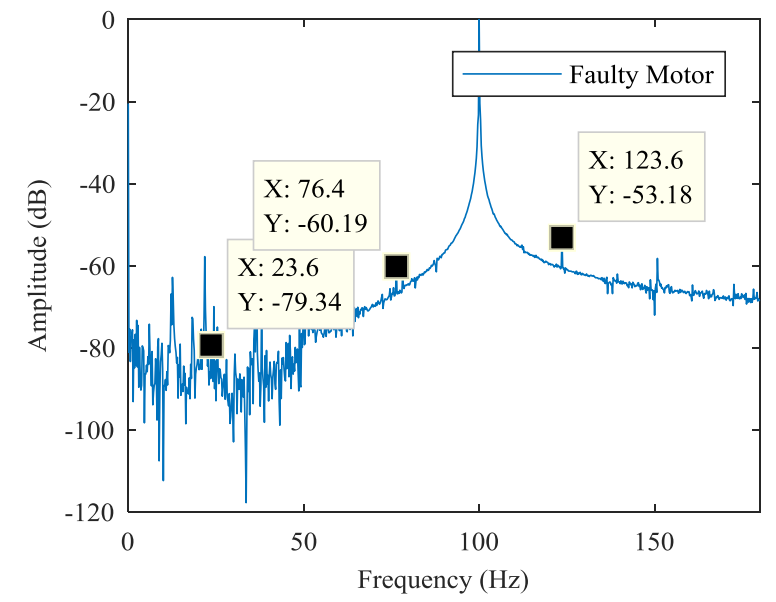

(b)

Fig. 3.The instantaneous power spectra of the (a) healthy gear (b) faulty gear
Table II. Summary of the Amplitude Variations for Healthy and Faulty Gear in Instantaneous Power Spectra

\begin{tabular}{|c|c|c|}
\hline $\begin{array}{c}\text { Amplitude Values } \\
\text { for Healthy Gear }\end{array}$ & $\begin{array}{c}\text { Amplitude Values } \\
\text { for Faulty Gear }\end{array}$ & $\begin{array}{c}\text { Difference in } \\
\text { Amplitude (dB) }\end{array}$ \\
\hline $\begin{array}{c}-86.44,-67.43,- \\
60.68\end{array}$ & $\begin{array}{c}-79.34,-60.19,- \\
53.18\end{array}$ & 7 \\
\hline
\end{tabular}

B. Case study 2: Gear fault analysis using motor stator current spectra

Although the stator current analysis of gear defects under full load conditions has been investigated in various studies. However, the use of motor stator current analysis for gear faults analysis under medium loads has never been investigated in previous reported research. Thus, this paper has attempted to analyze the gear faults in medium load conditions.

The stator current analysis of the motor-coupled gear are shown in Figure 4. The amplitude values at harmonic frequencies (26.4 $\mathrm{Hz}$ and $73.6 \mathrm{~Hz}$ ) for the healthy gear are observed to be -73.84 $\mathrm{dB}$ and $-64.43 \mathrm{~dB}$. While the amplitude values for the faulty gear are shown to be $-70.27 \mathrm{~dB},-61.13 \mathrm{~dB}$. Thus, a total of $3 \mathrm{~dB}$ change in the amplitude has been observed as we replace the healthy gear with the faulty gear.

The summary of the amplitude variations at gear defect frequencies has been given in Table III.

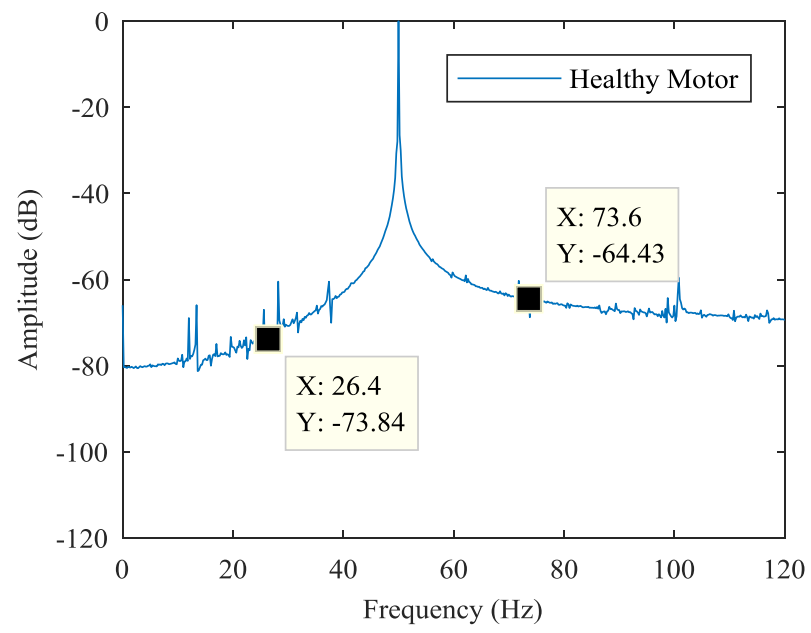

(a) 


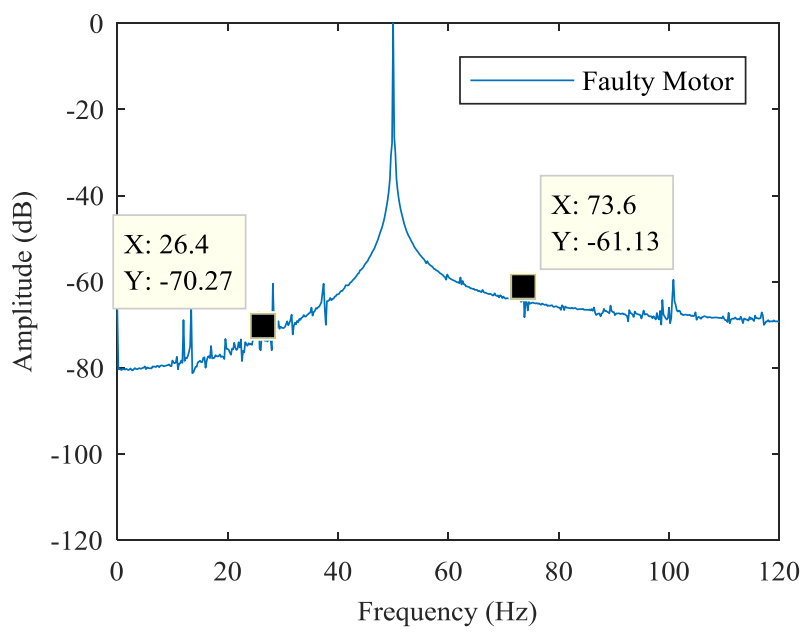

(b)

Fig. 4.The motor stator current spectra of (a) healthy gear (b) faulty gear

Table III. Summary of the Amplitude Variations for Healthy and Faulty Gear in Stator Current Spectra

\begin{tabular}{|c|c|c|}
\hline $\begin{array}{c}\text { Amplitude Values } \\
\text { for Healthy Gear }\end{array}$ & $\begin{array}{c}\text { Amplitude Values } \\
\text { for Faulty Gear }\end{array}$ & $\begin{array}{c}\text { Difference in } \\
\text { Amplitude (dB) }\end{array}$ \\
\hline$-73.84,-64.43$ & $-70.27,-61.13$ & 3 \\
\hline
\end{tabular}

The comparison of amplitude variations presented in Table I and II shows that the instantaneous power analysis technique has more sensitivity to faults as compared to stator current analysis technique. Also, the availability of three fault related harmonics in the instantaneous power spectra enhances its reliability for online fault diagnosis applications.

\section{Conclusions}

This paper has compared the two non-invasive techniques for the reliable diagnosis of the gear faults operating under medium load conditions. The non-invasive condition monitoring system has been developed using the hardware and software integration of the transducers using data acquisition system and LabVIEW. It has been shown that both stator current analysis and instantaneous power analysis techniques have capability to diagnose the gear faults. However, instantaneous power spectra has high sensitivity to amplitudes of gear fault harmonics. It has been concluded that the instantaneous power spectra has three fault related harmonics and is more suitable for reliable condition monitoring applications.

\section{References}

[1] Nooli P. K., "A versatile and computationally efficient condition indicator for AH-64 rotorcraft gearboxes," Degree of Master of Science University of South Carolina, 2011.

[2] Al-Arbi, Salem, "Condition monitoring of gear systems using vibration analysis," Doctoral thesis, University of Huddersfield, 2012.

[3] Henao, H., Kia, S.H., Capolino, G.-A.: Torsional vibration assessment and gear fault diagnosis in railway traction system. IEEE Transactions on Industrial Electronics, vol. 58, issue 5, pp. 1707-1717, 2011.

[4] Kar, C., Mohanty, A.R.: Vibration and current transient monitoring for gearbox fault detection using multiresolution Fourier transform. Journal of Sound and Vibration, vol. 311, pp. 109-132, 2008.

[5] Kia, S.H., Henao, H., Capolino, G.-A.: Analytical and experimental study of gearbox mechanical effect on the induction machine stator current signature. IEEE Transactions on Industrial Electronics, vol. 45, issue 4, pp. 1405-1415, 2009.

[6] Kia, S.H., Henao, H., Capolino, G.A.: Gear tooth surface damage fault detection using induction machine stator current space vector analysis. IEEE Transactions on Industrial Electronics, vol. 62, issue 3, pp. 1866-2001, 2015.

[7] Kia, S.H., Henao, H., Capolino, G.-A.: Development of a test bench dedicated to condition monitoring of wind turbines, IEEEIECON, Dallas (TX, USA), November 2014.

[8] Irfan, M., Saad, Asirvadam, V.S, "A non invasive method for condition monitoring of induction motors operating under arbitrary loading conditions," Arabian Journal of Science and Engineering, vol. 41, issue 9, pp. 3463-3471, 2016.

[9] Muhammad Irfan, Nordin Saad, Rosdiazli Ibrahim, Vijanth S Asirvadam, Alwadie A, Nursynrizal and M. Aman "A hardware and software integration approach for development of a noninvasive condition monitoring systems for motor-coupled gears faults diagnosis," Modeling, Design and Simulation of Systems, vol. 751, pp. 642-655, August 2017.

[10] Muhammad Irfan, Nordin Saad, Rosdiazli Ibrahim and Vijanth S Asirvadam, "Condition monitoring of induction motors via instantaneous power analysis," Journal of Intelligent Manufacturing, vol. 28, issue 6, pp 1259-1267, August 2017. 